\title{
Combination of Quantitative Changes in Ionic Components to Enhance the Contractile Force during T-tubule Development
}

\author{
Maiko Wakita ${ }^{1,2}$, Hitomi I. Sano ${ }^{1,2}$, Yasuhiro Naito ${ }^{1,2,3}$, Masaru Tomita ${ }^{1,2,3}$ \\ ${ }^{1}$ Institute for Advanced Biosciences, Keio University, Kanagawa, Japan \\ ${ }^{2}$ Department of Environment and Information Studies, Keio University, Kanagawa, Japan \\ ${ }^{3}$ Systems Biology Program, Graduate School of Media and Governance, Keio University, Kanagawa, \\ Japan
}

\begin{abstract}
During rodent ventricular cell development, the sarcoplasmic reticulum (SR) is scarce and poorly organized. $\mathrm{A} \mathrm{Ca}^{2+}$ transient in embryonic ventricular cells depends mostly on $\mathrm{Ca}^{2+}$ influx through $\mathrm{L}$-type $\mathrm{Ca}^{2+}$ channels. In rat ventricular cells, transverse tubules ( $t$ tubules) begin to form postnatally. As such, $\mathrm{Ca}^{2+}$-induced $\mathrm{Ca}^{2+}$ release (CICR), in which ryanodine receptor channels on the SR are activated via $\mathrm{Ca}^{2+}$ influx through L-type $\mathrm{Ca}^{2+}$ channels on the t-tubules, is not established in embryonic ventricular cells. Here, we modeled developmental changes in guinea pig ventricular cells and identified the factors that enhance contraction of the cells with an increase in CICR.
\end{abstract}

\section{Introduction}

Spontaneous action potentials have been reported for the early embryonic (EE) stage in developing rodent ventricular myocytes, eventually disappearing to passive contracting cells in the late embryonic (LE) stage. Previous studies have demonstrated that the sarcoplasmic reticulum (SR) is scarce and poorly organized in EE ventricular cells [1]; in rats, the transverse tubules (ttubules) of the ventricular cells begin to form postnatally [2]. In addition, $\mathrm{Na}^{+}-\mathrm{Ca}^{2+}$ exchange plays an important role in neonatal cells with a morphologically sparse SR.

The relative significance of $\mathrm{Ca}^{2+}$ release from the SR changes during the postnatal maturation of ventricular cells. Electron microscopic observation of rat ventricular cells has shown that the SR increases rapidly by 5-fold during early postnatal maturation, and that the SR to sarcolemma (SL) ratio reaches the adult level in a 22-dayold rat [1] (Figure 1). The relative extent of SR maturation is highly correlated with gestational age; the guinea pig heart exhibits a more extensive SR at birth compared to the rabbit heart [3], and postnatal development increases the immature SR of the rabbit heart by approximately 3-fold [4]. Quantitative changes in the levels of SR-related proteins [5-7] are roughly proportional to changes in the SR volume [1], indicating that the functional significance of the SR in cardiac $\mathrm{Ca}^{2+}$ regulation is enhanced during morphological maturation as well as by increasing the levels of SR-related proteins. The developmental changes in the inward rectifying $\mathrm{K}^{+}$ current $\left(I_{\mathrm{K} 1}\right), \mathrm{Na}^{+}-\mathrm{Ca}^{2+}$ exchange, and SR Ca ${ }^{2+}$ pump corresponding to gestational periods of the rat, rabbit, and guinea pig are summarized in the schematic diagram in Figure 2.
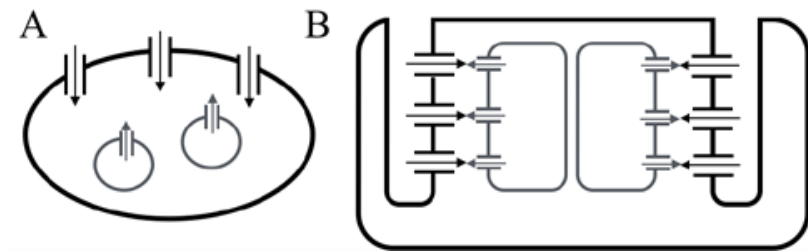

Figure 1. Schematic diagram of (A) an embryonic ventricular cell with a poorly organized sarcoplasmic reticulum and no t-tubule, and (B) an adult ventricular cell with developed t-tubules and established $\mathrm{Ca}^{2+}$ induced $\mathrm{Ca}^{2+}$ release.

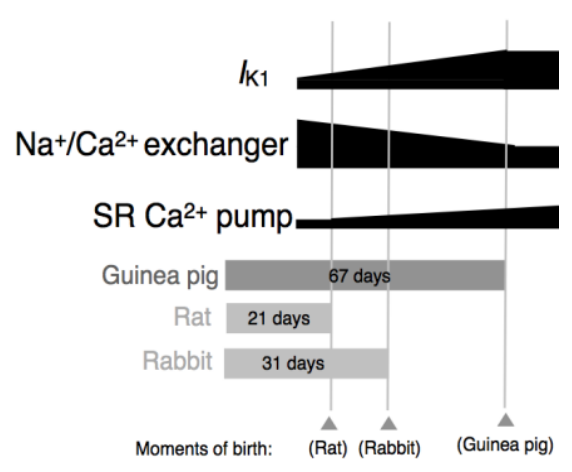

Figure 2. Developmental changes in current densities of inward rectifying $\mathrm{K}^{+}$current $\left(I_{\mathrm{K} 1}\right), \mathrm{Na}^{+}-\mathrm{Ca}^{2+}$ exchange, and SR $\mathrm{Ca}^{2+}$ pump along with the gestational periods of the rat, rabbit, and guinea pig. 
We have previously modeled the developmental changes in action potentials of rodent ventricular cells [8] and made various combinations of the model via switching ionic current densities of 9 ionic components to describe the contribution of each factor to the changes in action potential [9], based on the Kyoto model [10]. In this study, we integrated the estimated current densities to model embryonic guinea pig ventricular cells and assumed a "middle embryonic" (ME) stage in addition to the early embryonic (EE) and late embryonic (LE) stages that we have modeled in our previous studies $[8,9]$.

\section{Methods}

As shown in Figure 2, the gestational period of the guinea pig is relatively longer than that of the rat and rabbit. We first defined the EE stage as 9-11 days postconception (dpc) and the LE stage as approximately 60 dpc. The long embryonic period of guinea pig ventricular cell development was divided into $10 \%$ increments starting from $0 \%$ (EE) to $100 \%$ (LE) (Figure 3). We then assumed that mice and rats at approximately $18 \mathrm{dpc}$ roughly represent the stage corresponding to the $20 \%$ mark, and integrated ionic current densities obtained from mice and rats. Figure 3 summarizes the quantitative changes in representative ionic components in the model, and Tables 1 and 2 show the relative ratios for ionic currents and those for ion fluxes in the exchanger, pump, and SR $\mathrm{Ca}^{2+}$ fluxes, respectively. As adult ventricular cells have no funny current $\left(I_{\mathrm{f}}\right)$ nor a sustained current $\left(I_{\mathrm{st}}\right)$, we estimated the conversion factors for these currents based on current-voltage curves of the currents in 9.5- and 18.5-dpc mouse ventricular cells (Table 3).

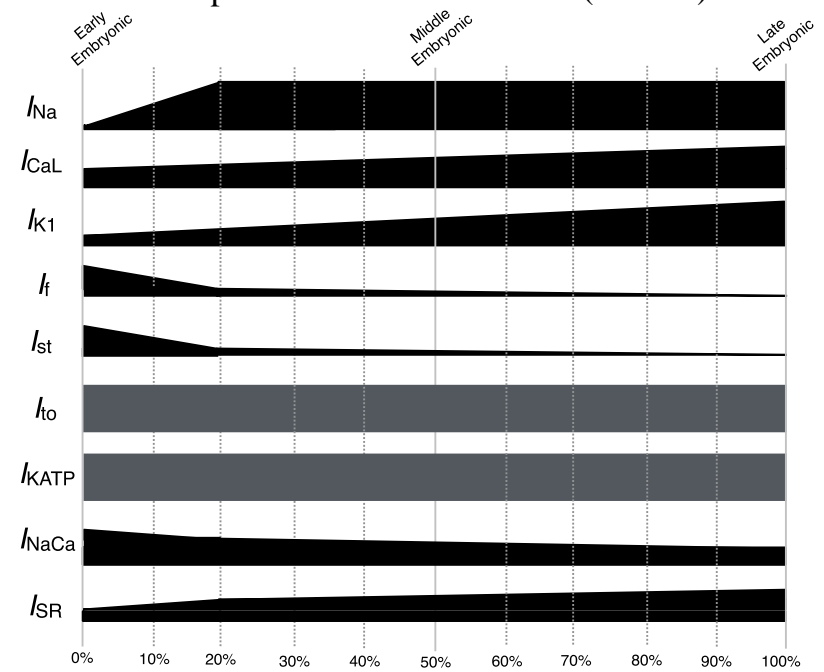

Figure 3. Developmental changes in ionic current densities of various ionic components. The embryonic period was separated by increments of $10 \%$ from $0 \%$ (early embryonic, EE) to $100 \%$ (late embryonic, LE). The "middle embryonic" (ME) stage was defined as 50\%.
Table 1. Relative current densities for ionic currents

\begin{tabular}{cccc}
\hline Ionic channels & $\mathrm{EE}$ & $\mathrm{ME}$ & $\mathrm{LE}$ \\
\hline$I_{\mathrm{Na}}$ & 0.07 & 1.0 & 1.0 \\
$I_{\mathrm{CaL}}$ & 0.46 & 0.68 & 0.78 \\
$I_{\mathrm{K} 1}$ & 0.11 & 0.625 & 1.0 \\
$I_{\mathrm{Kr}}$ & 2.0 & 1.36 & 0.3 \\
$I_{\mathrm{KATP}}$ & 1.0 & 1.0 & 1.0 \\
$I_{\mathrm{to}}$ & 1.0 & 1.0 & 1.0 \\
\hline
\end{tabular}

Table 2. Relative ratios for ion fluxes in the exchanger, pump, and sarcoplasmic reticulum (SR) $\mathrm{Ca}^{2+}$ fluxes

\begin{tabular}{cccc}
\hline Ionic components & EE & ME & LE \\
\hline $\mathrm{Na}^{+} / \mathrm{Ca}^{2+}$ exchange current & 4.95 & 2.25 & 1.0 \\
$\mathrm{SR} \mathrm{Ca}^{2+}$ pump & 0.03 & 0.394 & 0.7 \\
$\mathrm{RyR}$ channel & 0.05 & 0.513 & 0.7 \\
$\mathrm{SR} \mathrm{Ca}^{2+}$ transfer & 0.04 & 0.45 & 0.7 \\
$\mathrm{SR} \mathrm{Ca}^{2+}$ leak & 0.04 & 0.45 & 0.7 \\
$\mathrm{CICR}$ factor & -3.0 & -76.9 & -105 \\
\hline
\end{tabular}

Table 3. Estimated conversion factors for $I_{\mathrm{f}}$ and $I_{\mathrm{st}}$

\begin{tabular}{cccc}
\hline $\begin{array}{c}\text { Parameter } \\
(\mathrm{pA} / \mathrm{pF} / \mathrm{mM})\end{array}$ & EE & ME & LE \\
\hline$P_{\mathrm{f}, \mathrm{Na}}$ & 0.0186165 & 0.0020944 & 0 \\
$P_{\mathrm{f}, \mathrm{K}}$ & 0.0760725 & 0.0085582 & 0 \\
$P_{\mathrm{st}, \mathrm{Na}}$ & 0.0048438 & 0.0005449 & 0 \\
$P_{\mathrm{st}, \mathrm{K}}$ & 0.0029106 & 0.0003274 & 0 \\
\hline
\end{tabular}

To assess the effect of quantitative changes in various components of the model as the t-tubule develops, we varied the "CICR" factor, which affects the transition from a closed state to an open state, of the ryanodine receptor (RyR) channel (Figure 4).

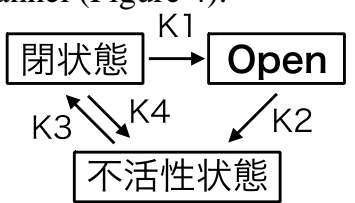

Figure 4. Transition among three states of the ryanodine receptor (RyR) channel

$$
\begin{aligned}
& k_{1}=280000 \cdot\left[\mathrm{Ca}^{2 *}\right]_{4}^{2}-150 * i_{\mathrm{Cal}} \cdot p\left(\text { open }_{\mathrm{Cal}}\right) \\
& k_{2}=\frac{0.08}{\left(1+0.36 \sqrt{\left.\left.\mathrm{Ca}^{2+}\right]_{\text {rel }}\right)}\right.} \\
& k_{3}=0.000377 \cdot\left[\mathrm{Ca}^{2 *}\right]_{\text {rel }}^{2} \\
& k_{4}=0.000849
\end{aligned}
$$


All models were first simulated for $600 \mathrm{~s}$, and the combinations that resulted in quiescent membrane potentials were externally stimulated by potassium ions at a frequency of $2.5 \mathrm{~Hz}$ for $600 \mathrm{~s}$ to pace the model. All simulations were based on the Dormand-Prince method as implemented in E-Cell Simulation Environment version 3 [11].

\section{Results and Discussion}

Figure 5 shows changes in the amplitudes of half sarcomere lengths with an increasing CICR parameter, which represents t-tubule development. The amplitudes of half sarcomere lengths in ventricular cells at the ME stage were lower than those at the LE stage. This result is contradictory to the observation that the contractile force increases as ventricular cells develop; however, the contradiction merely reflects the fact that an increase in contractile proteins was not represented in the model. As such, the simulated results shown in Figure 5 are not quantitatively accurate; thus, we can only discuss the result on a relative basis.

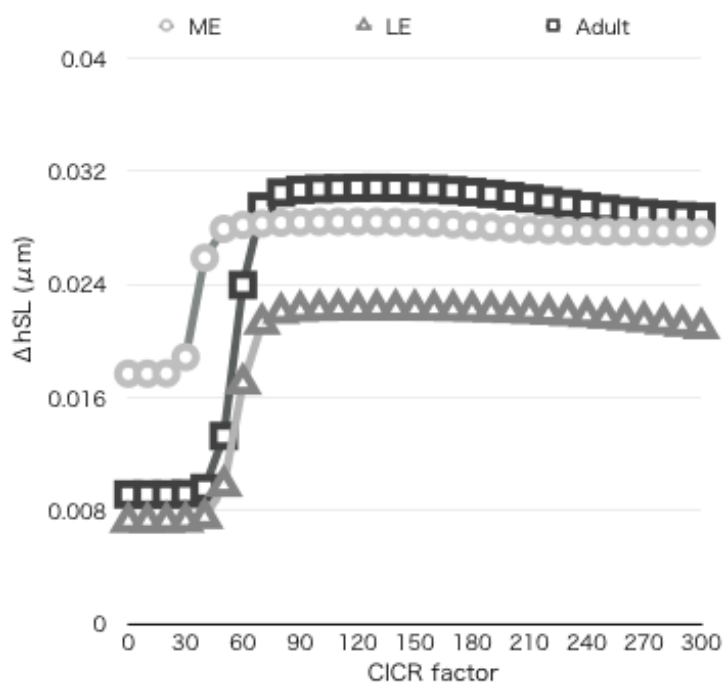

Figure 5. Changes in the amplitudes of half sarcomere length with an increase in the $\mathrm{Ca}^{2+}$-induced $\mathrm{Ca}^{2+}$ release (CICR) factor of the middle embryonic (ME, circles), late embryonic (LE, triangles), and adult (squares) ventricular cells.

As we increased the CICR parameter, which represents t-tubule development, from 0 to 300 , the amplitudes of changes in half sarcomere lengths were increased in all models: ME, LE, and adult models (Figure 5). The effect of increasing the CICR parameter was greatest in the adult model; the amplitude was approximately $0.009 \mu \mathrm{m}$ when the CICR parameter was set to 0 and exponentially increased to $0.032 \mu \mathrm{m}$, which is more than a 3 -fold increase, when the parameter was set to 90 . Similarly, in the LE model, the amplitude increased from $0.007 \mu \mathrm{m}$ to $0.023 \mu \mathrm{m}$ as the CICR parameter was changed from 9 to 90.

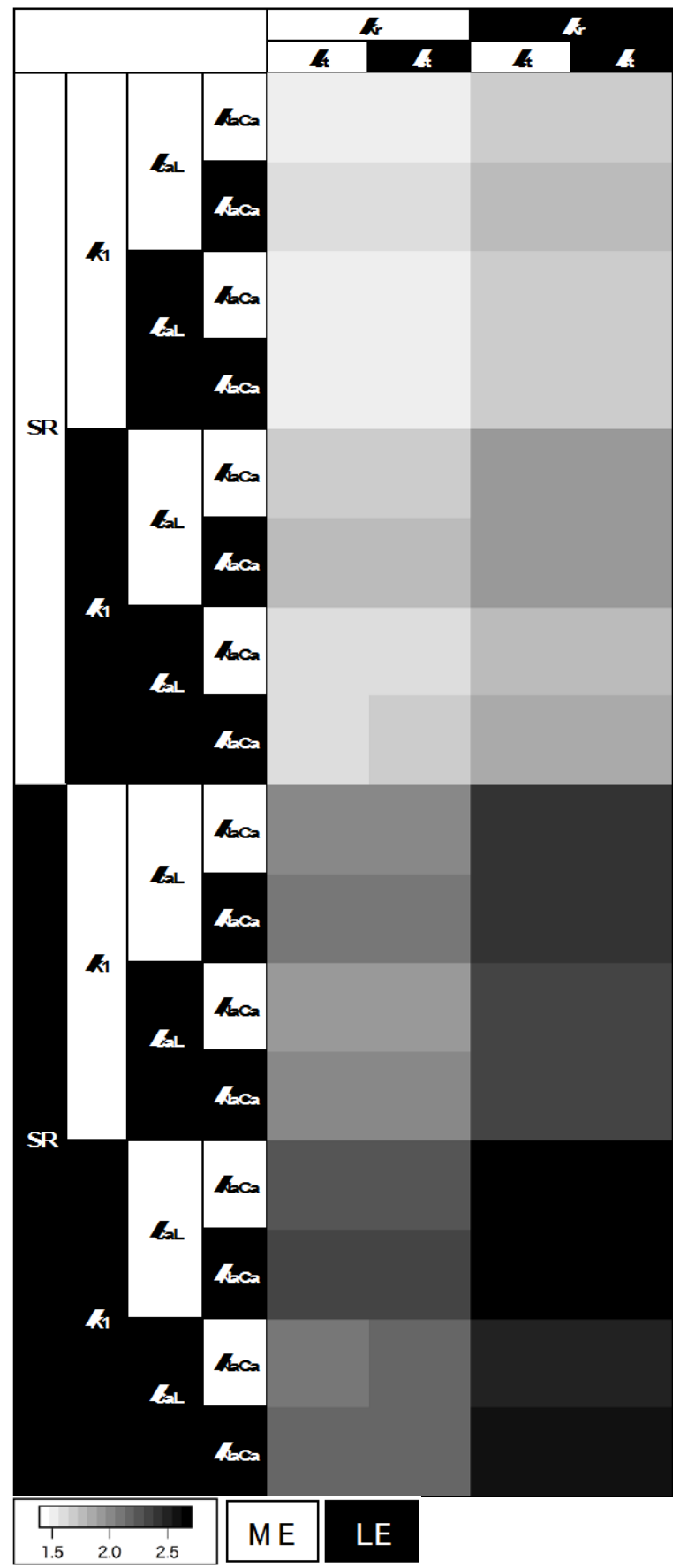

Figure 6. Relative changes in the amplitudes of half sarcomere length when changing the $\mathrm{Ca}^{2+}$-induced $\mathrm{Ca}^{2+}$ release (CICR) factor from 0 to 150 . Black letters in white boxes represent relative current densities that were set to the middle embryonic (ME) stage, and white letters in black boxes represent those set to the late embryonic (LE) stage. 
To identify the factors that contribute to enhancing the contractile force from the ME to LE stages, we used combinations in which the relative current densities were switched independently from ME to LE values. Figure 6 summarizes the simulated relative changes in the amplitudes of half sarcomere lengths when changing the CICR parameter from 0 to 150 in 64 combinations of the models. An increase in SR-related factors resulted in the largest change in the amplitude of half sarcomere length with a larger CICR parameter. By contrast, an increase in the L-type $\mathrm{Ca}^{2+}$ current density had a negative impact on the amplitude as the CICR parameter increased. The remaining ionic components, including $I_{\mathrm{K} 1}$ and the rapid component of delayed rectifying $\mathrm{K}^{+}$current $\left(I_{\mathrm{Kr}}\right)$, contributed to increasing the contractile force during ttubule development, indicating that changes in membrane potential indirectly affect the contractile force and are also related to t-tubule development.

\section{Conclusions}

We modeled developmental changes in guinea pig ventricular cells and identified the factors that enhance contraction of the cells with an increase in CICR. From the middle to late embryonic stages in guinea pig ventricular cells, almost all factors, except for an increase in the L-type $\mathrm{Ca}^{2+}$ current density, contributed to increasing the amplitude of half sarcomere length along with an increase in the CICR parameter.

\section{Acknowledgements}

This work was supported by funds from the Yamagata Prefectural Government and Tsuruoka City and Keio Gijuku Academic Development Funds. We thank the members of the E-Cell Project at the Institute for Advanced Bioscience, Keio University, for their critical suggestions.

\section{References}

[1] Olivetti G, Anversa P, Loud AV. Morphometric study of early postnatal development in the left and right ventricular myocardium of the rat. II. Tissue composition, capillary growth, and sarcoplasmic alterations. Circ Res 1980;46:503-12.

[2] Seki S, Nagashima M, Yamada Y, Tsutsuura M, Kobayashi T, Namiki A, Tohse N. Fetal and postnatal development and $\mathrm{Ca} 2+$ transients and $\mathrm{Ca} 2+$ sparks in rat cardiomyocytes. Cardiovasc Res 2003;58:535-48.

[3] Artman M, Ichikawa H, Avkiran M, Coetzee WA. $\mathrm{Na}^{+}-\mathrm{Ca}^{2+}$ exchange current density in cardiac myocytes from rabbits and guinea pigs during postnatal development. Am J Physiol 1995;268:171422.
[4] Chen F, Ding S, Lee BS, Wetzel GT. Sarcoplasmic reticulum $\mathrm{Ca}^{2+}$-ATPase and cell contraction in developing rabbit heart. J Mol Cell Cardiol 2000;32:745-55.

[5] Liu W, Yasui K, Opthof T, Ishiki R, Lee JK, Kamiya K, Yokota M, Kodama I. Developmental changes of $\mathrm{Ca}^{2+}$ handling in mouse ventricular cells from early embryo to adulthood. Life Sci 2002;71:1279-92.

[6] Harrer JM, Haghighi K, Kim HW, Ferguson DG, Kranias EG. Coordinate regulation of SR $\mathrm{Ca}^{2+}-$ ATPase and phospholamban expression in developing murine heart. Am J Physiol 1997;272:5766.

[7] Vetter R, Studer R, Reinecke H, Kolar F, Ostadalova I, Drexler H. Reciprocal changes in the postnatal expression of the sarcolemmal $\mathrm{Na}^{+}-\mathrm{Ca}^{2+}$-exchanger and SERCA2 in rat heart. J Mol Cell Cardiol 1995;27:1689-701.

[8] Itoh H, Naito $Y$, Tomita M. Simulation of developmental changes in action potentials with ventricular cell models. Syst Synth Biol 2007;1:1123.

[9] Okubo C, Sano HI, Naito Y, Tomita M. Contribution of quantitative changes in individual ionic current systems to the embryonic development of ventricular myocytes: a simulation study. J Physiol Sci 2013;63:355-67.

[10] Kuzumoto M, Takeuchi A, Nakai H, Oka C, Noma A, Matsuoka S. Simulation analysis of intracellular $\mathrm{Na}^{+}$and $\mathrm{Cl}^{-}$homeostasis during beta 1-adrenergic stimulation of cardiac myocyte. Prog Biophys Mol Biol 2008;96:171-86.

[11] Takahashi K, Kaizu K, Hu B, and Tomita M. A multi-algorithm, multi-timescale method for cell simulation. Bioinformatics 2004;20:538-46.

Address for correspondence:

Hitomi I. Sano

5322 Endo, Fujisawa

Kanagawa 252-0882, Japan

ducky@sfc.keio.ac.jp 